\title{
Soil Contamination Rate, Prevalence, Intensity of Infection of Geohelminths and Associated Risk Factors among Residents in Bazou (West Cameroon)
}

\author{
Blandine Ngatou Tchakounté ${ }^{1 *}$, Vanessa Rosine Nkouayep ${ }^{1}$, Josué Wabo Poné ${ }^{1}$
}

\section{OPEN ACCESS}

Citation: Ngatou Tchakounté Blandine, Nkouayep Vanessa Rosine, Wabo Poné J Soil Contamination Rate, Prevalence, Intensity of Infection of Geohelminths and Associated Risk Factors among Residents in Bazou (West-Cameroon). Ethiop J HealthSci.2017;27(6):63. doi:http://dx.doi.org/10.4314/ejhs.v28i1. 8

Received: May 24, 2017

Accepted: May 26, 2017

Published: November 1, 2017

Copyright: (C) 2017 Ngatou. T.B., et al. This is an open access article distributed under the terms of the Creative Commons Attribution License, which permits unrestricted use, distribution, and reproduction in any medium, provided the original author and source are credited.

Funding: Nil

Competing Interests: The authors declare that this manuscript was approved by all authors in its formand that no competing interest exists. Affiliation and Correspondence: ${ }^{1}$ Laboratory of Biology and Applied Ecology, Department of Animal Biology, Faculty of Science, University of Dschang, Dschang, Cameroon

*Email:ngatoub@yahoo.com
ABSTRACT

BACKGROUND: Soil-transmitted helminths (STH) infections remain an important public health problem in the tropics. This study aimed to evaluate the soil contamination rate and prevalence of infestations of geohelminth among residents in Bazou.

METHODS: Four hundred (400) soil samples and 182 stool specimens were collected respectively from four sites and from inhabitants aged 1 to 40 years and above in 12 households. A questionnaire was administered to evaluate risk factors of STHinfections. Soil samples were screened using sucrose centrifugal flotation method while stool specimens were analyzed using two techniques.

RESULTS: Out of the 400 soil and 182 stool samples examined, 13(3.3\%) and 9(4.95\%) were positive respectively after analyses. Soil contamination rates were $2 \%, 1 \%$ and $0.3 \%$ for Ascaris, Trichuris and hookworm eggs respectively while $4.95 \%$ of stool samples were positive to one species nematode (Ascaris lumbricoides). The soil contamination rate observed (5\%) in the rainy season was significantly different $(p>0.05)$ from the one observed (1.5\%) in the dry season. Irrespectively of the season, the most frequent parasite identified was Ascaris spp. Soils around houses were more contaminated 6(12\%) as compared to those collected from markets $5(10 \%)$ and roads $2(4 \%)$ while those around classrooms were not contaminated. Participants in the age group of 1-10 were more infected. Factors such as no hand washing habit and untrimmed finger nails were found to be important risk factors for $S T H$.

CONCLUSION: These results suggest the necessity to promote measures that could help to reduce $S T H$ infections.

KEYWORDS: Soil contamination, geohelminths, risk factors, Bazou, Cameroon

KEYWORDS: Sub-optimal breast feeding, Hula District 


\section{INTRODUCTION}

Soil contamination with parasite eggs, infective larvae, cysts and oocysts constitutes the most important risk factor for some human parasitic infections (1). Soil-transmitted helminths (STH) are a group of intestinal nematodes composed of Ascaris lumbricoides (roundworm), Trichuris trichiura (whipworm), Necator americanus and Ancylostoma duodenale (hookworms). In the life cycle of these nematodes, the soil provides favorable conditions for the development of infective stages. Also, the soil gives protection for the infective stages for a period, during which it may be brought into contact with a susceptible individual through the mouth or the skin (2). Parasite eggs or larvae survive in the warm and moist soil of the tropical and subtropical countries. The number of years lost due to ill-health, disability or early death all over the world is range from 4.7 million to 39 million (3). Soiltransmitted helminths have been identified as a serious public health problem predominantly among school children (4). The adverse effects of intestinal parasites among children are divers and alarming. Intestinal parasitic infections have detrimental effects on the survival, appetite, growth and physical fitnesses, school attendance and cognitive performance of school age children (5). Also, these infections may increase susceptibility to infections with other pathogens (6). An estimated 807-1,221 million people in the world are infected with Ascaris lumbricoides (sometimes called just "Ascaris"), 604-795 million with whipworm and 576-740 million with hookworm. It has been estimated that 65.000 deaths occurring in the world is due to Ascaris lumbricoides, 70.000 due to Trichuris trichiura and 60.000 due to hookworms (7).

Surveys conducted in Mexico revealed that 35.2 million children of school age are infected with helminths (8). In Ivory-Coast, about 36\% children of school age are infected with STH while. In Cameroon, these infections are among the most important parasitic diseases (9). Efforts have been made in this country to reduce the parasitic burden in the population using mass drug administration (MAD) of anthelminthics in primary schools. Debalké et al. (10) revealed that several factors such as soil contamination, absence of sanitary facilities, unsafe waste disposal system, inadequacy and lack of safe water supply, types of toilet and human factors including age, sex, socioeconomic status and occupation influence the development and the distribution of STH eggs. Thus, researches should be conducted to know the different sources responsible for helminth infections in order to struggle better control measures. Keeping the above facts into consideration, this study aimed to know the health status of soils, prevalence, intensity of infections and risk factors associated with geohelminth infections in Bazou.

\section{METHODS}

Study design and period: This study was a cross sectional prevalence study. The study was conducted from September - October 2013 rainy season and from March - April 2014 dry season on the soils and among inhabitants of Bazou, Ndé Division, West Region, Cameroon. The practical work was done at the Research Unit of the Biology and Applied Ecology (LABEA) units of the Department of Animal Biology in the Faculty of Science, University of Dschang, Cameroon.

Study area: Bazou is a village situated in the Ndé division (West Cameroon). It is located between $5^{\circ} 05^{\prime} 97^{\prime} ' \mathrm{~N}$ and $10^{\circ} 46^{\prime} 81^{\prime \prime} \mathrm{E}$. The mean temperature in this area is between $15.8^{\circ} \mathrm{C}$ and $24.5^{\circ} \mathrm{C}$ with a peak reaching $37^{\circ} \mathrm{C}$. It is characterized by a tropical climate type. Cameroon Water Supply (CDE) is a company which supplies water through pipeline. However, there are other drinking spots like streams, springs and wells, because not everybody has access to the CDE pipeline water supply. The water is being kept in houses inside buckets without introducing any chemical. Streams are surrounded by muddy and sandy soils. Most toilets usage do not respect hygienic conditions, and some of the toilets are closer to drinking spots. The main economic activity of population of Bazou is agriculture. The soil of Bazou varies (muddy and sandy), but most of it is sandy, moist with decaying vegetation and

DOI: http://dx.doi.org/10.4314/ejhs.v28i1.8 
contaminated with human faeces resulting in sewage pollution. Considering these factors, the environment is suitable for both the free living and parasitic mode of life of geohelminths. A deworming biannual mass drug administration with albendazole is ongoing in primary schools of Bazou (11).

Collection samples: A pre-tested questionnaire was developed and direct interview was administrated to the participants. The interview incorporated information on socio-demographic and sanitation factors such as age, sex, source of drinking water, presence and type of latrine, eating foods on ground, family educational level, family occupation and family size. During the interview, the interviewer also inspected the foot wear and finger nails of the children. To ensure the reliability of the information, children were interviewed using their mother tongue «medumba».

\section{Collection and examination of soil samples:}

Four hundred (400) soil samples (200 in dry season and another 200 in rainy season) were collected from various sites in Bazou by a sampling rational collection: along the roads of the village, behind houses, classrooms and the market houses. These sites were choosen because they are susceptible to be used by individuals as toilets based on the pre-test questionnaire result. Each sampling spot was separated from one another by a distance of $60 \mathrm{~m}$. About $200 \mathrm{gs}$ of each sample were collected from different areas not exposed to direct sunlight from $3 \mathrm{~cm}$ ground depth $(12,1)$. They are taken from a depth about $50 \mathrm{~cm}$ from the surface and weighed approximately. The soil samples were stored in airtight plastic bags labeled with numbers and transferred to the Research Unit of the Biology and Applied Ecology (LABEA) units under strict measures in a car (to avoid any extra contamination) where parasitological studies were performed on them. In the laboratory samples were dried overnight at room temperature in a shaded place. Soil samples were sieved through 150- $\mu \mathrm{m}-\mathrm{mesh}$, and $2 \mathrm{~g}$ of powdered soil were weighed four times and put in test tubes each mixed with $13 \mathrm{ml}$ distilled water. These tubes were centrifuged at $100 \mathrm{rpm}$ for $05 \mathrm{~min}$. The supernatant was discarded. Sediment of each tube was homogenized with the same volume of distilled water and centrifuged at 800rpm for $05 \mathrm{~min}$ and the supernatants were discarded again. Afterwards, the tubes were filled with sucrose solution $(\mathrm{d}=1.12)$ (this technique is $100 \%$ efficient as compare to direct examination) vigorously shaken and centrifuged at $100 \mathrm{rpm}$ for $05 \mathrm{~min}$. The supernatants were transferred in four other tubes until the fluid raised up to the brim of the tubes. Then, cover slips were placed on top tubes and left for $10 \mathrm{~min}$. After this period, the cover slips were delicately removed and placed on slides for microscopic observation (10 X and $40 \mathrm{X}$ ).

Sample size, collection and examination of fecal samples: The sample size of the study was estimated using the technique described by Daniel (13). $N=Z^{2} . P(1-p) / D^{2}$, where $N=$ minimum number of sample size, $Z^{2}=$ standard value, $P=$ expected prevalence of intestinal parasitic infections in the study area and $\mathrm{D}=$ marginal error, at $95 \%$ confidence interval: $\mathrm{Z}=1.96$ and $\mathrm{D}=$ 0.05 since no report was recorded for infection prevalence of intestinal parasitic infections in the area, $\mathrm{P}=80 \%$. Accordingly, $\mathrm{N}=(1.96)^{2} \times 0.8(1$ $0.8) /(0.05)^{2}=245$.

One hundred and eighty two (182) participants of all ages living in Bazou for at least 5 years were included in the study. In each family with more than or equal to 5 kids, a questionnaire was administered to a consenting person to assess the potential risk factors of infections with geohelminths. For fecal samples, a phial labeled (number, age and sex ) was given to the specific participant. In the morning, each fecal sample was recovered and suspended in 10\% formalin. All samples were stored in a plastic bag at room temperature and transported later to the LABEA where parasitological analyses were carried out using flotation technique with saturated salt

DOI: http://dx.doi.org/10.4314/ejhs.v28i1.8 
solution $(0.4 \%)$ (14). The intensity of infections was evaluated using the Mc Master technique (9). Parasitic stages were identified at the genus level using their morphological characteristics such as the form, the nature of egg shell and the number of blastomers $(15,16)$.

Data analysis: Soil contamination rates, prevalence and intensity of infections were compared using chi-square and the Student $t$ test respectively. Data were considered significant at $\mathrm{P}<0.05$.

Ethical consideration: The proposal for this study was approved by the West Regional Delegation of the Public Health and Cameroon Bioethics Initiation (CAMBIN).

\section{RESULTS}

Soil samples: Out of the 400 soil samples collected, 13 were positive to nematode eggs giving an overall contamination rate of $3.3 \%$. Ascaris spp. eggs were most frequent (2\%) followed by those of Trichuris spp. (1\%) and hookworms $(0.3 \%)$ eggs.

Site contamination-related rate: The contamination rate of samples collected from different sites is presented in Table 1. Soil samples collected around houses were most contaminated, $6(12 \%)$, followed by those from behind market houses, $5(10 \%)$ and along the roads, $2(4 \%)$. Soil samples collected around classrooms were not contaminated

Table 1: Contamination rates of sample sites by parasites encountered.

\begin{tabular}{|c|c|c|c|c|c|}
\hline \multirow[b]{2}{*}{ Parasites } & \multicolumn{4}{|c|}{ Sample sites } & \multirow[b]{2}{*}{$\begin{array}{l}\text { Total } \\
\text { n (\%) }\end{array}$} \\
\hline & Road & $\begin{array}{c}\text { Houses } \\
\mathrm{n}(\%)\end{array}$ & $\begin{array}{c}\text { Market } \\
\mathrm{n}(\%)\end{array}$ & $\begin{array}{c}\text { Schools } \\
\text { n (\%) }\end{array}$ & \\
\hline Ascaris spp & $2(4)$ & $2(4)$ & $4(8)$ & 0 & $8(2)$ \\
\hline Trichuris spp & 0 & $4(8)$ & 0 & 0 & $4(1)$ \\
\hline Hookworms & 0 & 0 & $1(2)$ & 0 & $1(0.3)$ \\
\hline
\end{tabular}

Table 2: Type and frequency of nematode eggs recorded in rainy and dry seasons.

\begin{tabular}{|c|c|c|c|}
\hline \multirow[b]{2}{*}{ Parasites } & \multicolumn{2}{|c|}{ Seasons } & \multirow[b]{2}{*}{$\begin{array}{l}\text { Total } \\
\text { n (\%) }\end{array}$} \\
\hline & $\begin{array}{l}\text { Rainy } \\
\text { n (\%) }\end{array}$ & $\begin{array}{c}\text { Dry } \\
\mathrm{n}(\%)\end{array}$ & \\
\hline Ascaris spp & $6(3)$ & $2(1)$ & $8(2)$ \\
\hline Trichuris spp & $3(3)$ & $1(0.5)$ & $4(1)$ \\
\hline Hookworms & $1(0.5)$ & 0 & $1(0.3)$ \\
\hline
\end{tabular}

Seasonal soil contamination-related rate: The seasonal soil contamination rate is shown in Table 2. Soil samples collected in the wet season, $10(5 \%)$ were significantly $(\mathrm{p}<0.05)$ more contaminated as compared to those collected in dry season, 3(1.5\%). Irrespectively of the season, Ascaris spp. eggs were more prevalent followed by those of Trichuris spp. and hookworms eggs.
Faecal samples: One hundred and eighty two (182) participants had answered to the questionnaires and had given their stool samples. Ninety four (94) were males and eighty eight (88) were females, a sex ratio of 0.94 . Out of the 182 stool samples collected, 09(4.95\%) were positive to only one species of nematodes (Ascaris lumbrivoides). 
Sex related prevalence: The prevalence of infection with Ascaris lumbrivoides in relation to sex is illustrated in Figure 1. Female participants were slightly more infected $(2.5 \%$ vs $2 \%)$ than male participants. Also, the parasitic load in terms of eggs per gram of feaces (EPG) was significantly $(p<0.05)$ higher in male participants $(537.5 \pm 719.2)$ as compared to female subjects $(270.0 \pm 67.1)$.

Age related prevalence: Participants of the age group between [1-10] had the highest prevalence of infection, followed by those of [30-40] (1.5\%) and those of [10-20] (0.5\%). Participants from age the groups 21-30 and $>40$ years were free from parasites. Differences between prevalences of different age groups were not statically significant (p>0.05) (Figure 2).

Seasonal infection related prevalence: Participants were more infected in the rainy season, 5(3\%), as compared to the dry season
$3(1.95 \%)$ without statistical differences $(\mathrm{p}>0.05)$ (Figure 3).

Risk factors: Table 3 shows presents on some risk factors evaluated in the study. A total of 182 households were enrolled in the study. In all selected households, a questionnaire was administered to each consent participants. From these data, it appears that about $84 \%$ of the participants defecate sometimes along the roads. Ninety-five percent (95\%) use tap water as potable water, and $96 \%$ had cement latrine while $36.1 \%$ school children had access to latrine facilities. As to hygienic conditions, $7.43 \%$ of the participants regularly washed hand before eating, $62.63 \%$ of the participants did not trim their finger nails. After analysis of some risk factors, improper hygienic practices like washing hands before meals and untrimmed finger nails were found to be significant $(\mathrm{p}<0.05)$ risk factors in acquiring soil transmitted helminths.

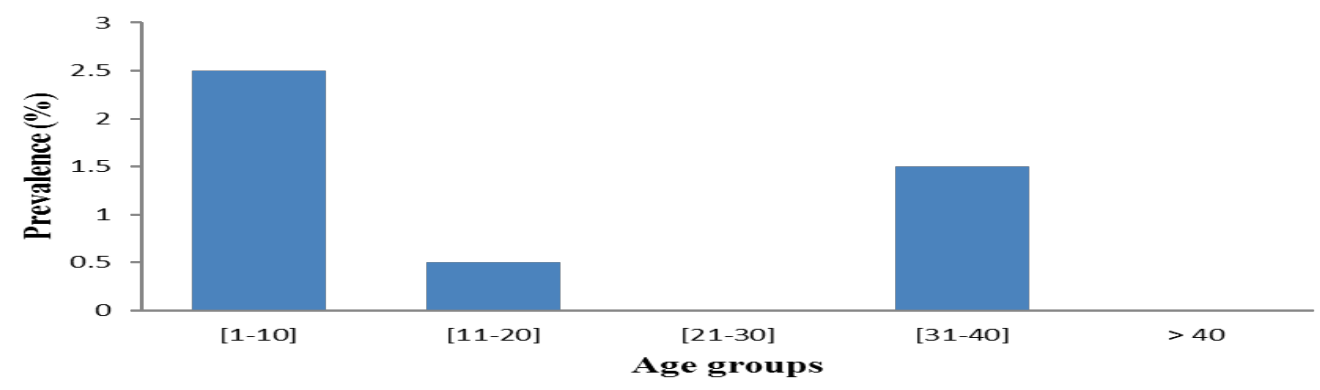

Figure 1: Prevalence of infestation of Ascaris lumbricoides according to sex

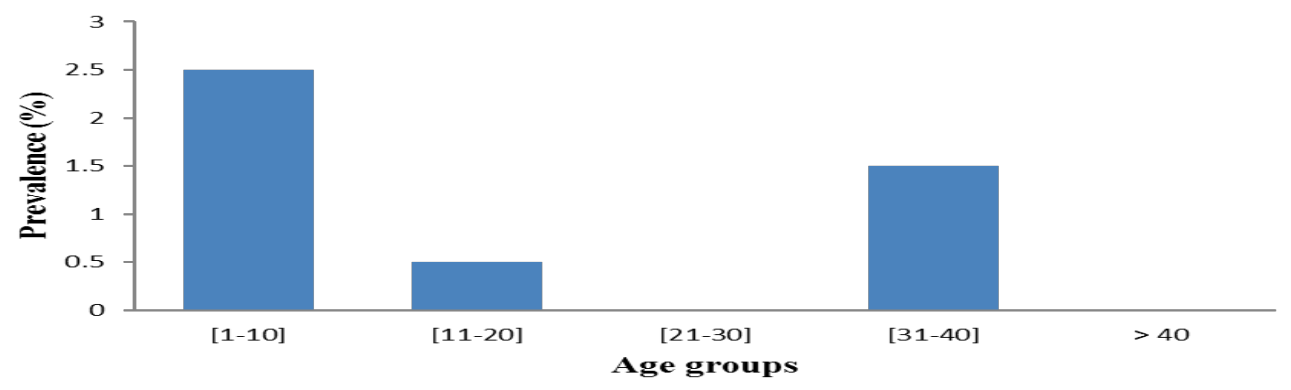

Figure 2: Prevalence of Ascaris lumbricoides infections among age group

DOI: http://dx.doi.org/10.4314/ejhs.v28i1.8 
Table 3: Risk factor and soil transmitted helminths infections among residents of Bazou.

\begin{tabular}{|c|c|c|c|c|c|}
\hline \multirow[b]{2}{*}{ Risk factors } & \multicolumn{3}{|c|}{ Ascaris } & \multirow[b]{2}{*}{$\mathrm{x}^{2}$} & \multirow[b]{2}{*}{$\mathrm{p}$-value } \\
\hline & $\begin{array}{l}\text { No* } \\
\text { No }(\%)\end{array}$ & $\begin{array}{l}\text { Yes } \\
\text { No }(\%)\end{array}$ & $\begin{array}{l}\text { Total } \\
\text { No }(\%)\end{array}$ & & \\
\hline \multicolumn{6}{|c|}{ Water source } \\
\hline Tap & $82(90,0)$ & $9(10,0)$ & $91(100)$ & & \\
\hline Source & $8(100)$ & $0(0)$ & $8(100)$ & 0,97 & 0,32 \\
\hline \multicolumn{6}{|c|}{ Type home latrine } \\
\hline Wood & $8(88,9)$ & $1(11,1)$ & $9(100)$ & & \\
\hline Cement & $82(91,1)$ & $8(8,9)$ & $90(100)$ & 0,11 & 0,92 \\
\hline \multicolumn{6}{|l|}{ Fingernails } \\
\hline Sometime & $12(92,3$ & $1(7,7)$ & $13(100)$ & & \\
\hline Always & $77(90,6$ & $8(9,4)$ & $85(100)$ & 9,028 & $0,01 *$ \\
\hline \multicolumn{6}{|c|}{ Hand washing habit } \\
\hline No & $6(100)$ & $0(0)$ & $6(100)$ & & \\
\hline Sometime & $20(76,9)$ & $6(23,1)$ & $26(100)$ & & \\
\hline Always & $64(95,5)$ & $3(4,5)$ & $67(100)$ & 6,75 & $0,03 *$ \\
\hline \multicolumn{6}{|c|}{ Eating food fallground } \\
\hline No & $59(90,8)$ & $6(9,2)$ & $65(100)$ & & \\
\hline Sometime & $27(90,0)$ & $3(10,0)$ & $30(100)$ & & \\
\hline Always & $4(100)$ & $0(0)$ & $4(100)$ & 0,84 & 0,654 \\
\hline \multicolumn{6}{|l|}{ Wearshoes } \\
\hline No & $34(91,9)$ & $3(8,1)$ & $237(100)$ & & \\
\hline Sometime & $38(88,4)$ & $5(11,6)$ & $43(100)$ & & \\
\hline Always & $18(94,7)$ & $1(5,3)$ & $19(100)$ & 1,354 & 0,508 \\
\hline Total & $90(89,9)$ & $9(9,1)$ & $99(100)$ & & \\
\hline
\end{tabular}

*No Ascaris seen in stools 


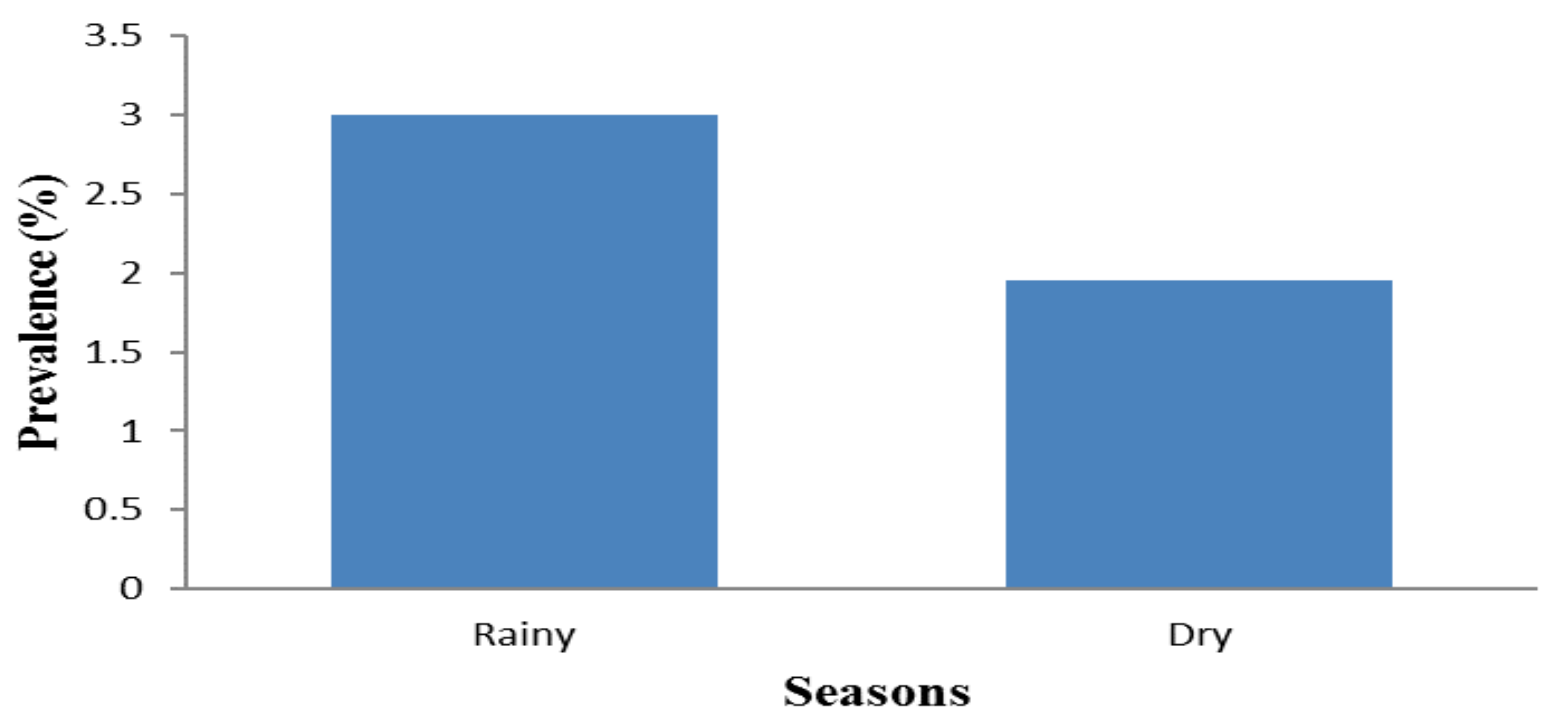

Figure 3: Seasonal distribution of Ascaris lumbricoides infections among participants

\section{DISCUSSION}

This survey aimed to evaluate the soil contamination rate of Bazou, prevalence, intensity of infections as well as risk factors associated with geohelminth infections in the population. Soil transmitted parasites have soil as a common medium for development of immature eggs and early stages of larvae of helminths, cysts and oocysts of protozoa (17). A total of 400 soil samples obtained from four different sites were examined. Out of the 400 samples, 13(3.3\%) were positive for geohelminths. This contamination rate is relatively low as compared to $11.25 \%$ and $28.5 \%$ obtained respectively by Debalké et al. (10) and Shrestha et al. (18) in their studies conducted in Jimma, Southwest Ethiopia, and in Katmandu (Nepal). The differences between these rates may be due to environmental factors such as climate, topography, temperature, type of soil, rainfall and the use of human feaces as fertilizer for crops (19).

In this study, the identification of STH eggs was limited to the genus level since the indetify parasite ova coming from men are similar with the animal ones. Thus, it was not possible for us to prove that these eggs came from humans or not. These STH were: Ascaris spp. (2\%), Trichuris spp. (1\%) and hookworms $(0.3 \%)$. These results are different from those obtained by Shrestha et al. (18) in Katmandu (Nepal) and by Bojar and Klapec (20) in the Lublin Region of Poland who identified additionally Strongyloides stercoralis and Toxocara spp. In these studies, Ascaris and Trichuris appear as the first and the second more prevalent geohelminths respectively. The relatively high prevalence of Ascaris spp. eggs in soil samples of this study is similar with other observations reported elsewhere $(18,21)$. This can be explained by the fact that eggs of Ascaris have an inner shell layer of lipoprotein nature which makes them more resistant to harsh environmental conditions and air-borne (22) compared to the eggs of other nematodes. Another reason is that Ascaris eggs can survival in adverse environmental conditions. It might also be due to the over dispersion of Ascaris eggs in the environment as a single female Ascaris lay relatively large number of eggs (200. 000 eggs/day) (16). Lower rate of soil contamination with Trichuris eggs observed might be due to their minimal dispersion as a single female Trichuris liberates relatively less numbers eggs (2000 egg per day) and also due to easy destruction of embryonated eggs by dessiccation.

Around houses, $1.5 \%$ of soil samples were more contaminated with the eggs of nematodes 
compared to the other three sampling points behind markets houses, $(1.25 \%)$, along the roads $(0.5 \%)$ and around classrooms (0\%). These findings could be due to the unhygienic and common practice of people defecating indiscriminately or dumping excrement everywhere (nearby bushes, along bush tracks, river banks and even on open fields) as noted by Olaniyi et al. (12). Proper use of latrines by students and the water flow at the level of hills can justify the absence of soil contamination in schools. In fact, all schools were located on hills and at this topographic position, the water flow contributes to the leaching of the soil with the eggs of parasites (23).

Seasonal and climatic conditions are important factors affecting the prevalence of geohelminths (24). This finding was proved in this study. Soil samples were relatively more contaminated during the wet season $(5 \%)$ with all three species of geohelminths encountered whereas in dry season $(1.5 \%)$, the soil was contaminated with only two species of nematodes identified. These results corroborate those obtained elsewhere $(25,26)$. Actually, it is known that the development of STH eggs in the outside environment, particularly in soil, is affected by several factors such as temperature (optimum 20$30^{\circ} \mathrm{C}$ ), humidity, $\mathrm{pH}$, depth and soil texture $(27 ; 28)$. These might affect their development by hastening their embryonation, viability, infectivity and size. This observation can be justified by the fact that the rains creating environmental and climatic conditions favorable for the survival of nematode eggs. However, these eggs are also resistant to extreme conditions. It is for this reason that few eggs of Ascaris spp. and Trichuris spp. were observed in the dry season.

Concerning stool samples, it was noticed that $4.95 \%$ of the study population were infected by only one species of geohelminths (Ascaris lumbricoides). These findings are too different from those obtained in most studies carried out over the world and in Cameroon in particular. For example, Chukwuma et al. (29) in Nigeria revealed, in their study, the presence of Ascaris spp. (54.1\%), hookworms (45.5\%), Trichuris spp.
(18\%) and Strongyloides stercoralis (5\%) larva. These parasites were also identified in the study carried out by Nkengazong et al. (30) in Southwest Region of Cameroon. The low prevalence obtained in this work could be due to the fact that about $95.60 \%$ persons take anthelminthics tablets during MAD campaign. Another reason is that they use tap water as drinking water. Richardson et al. (31) recommend that water supply obviously has an effect on the reduction of the rate of infection.

With respect to sex, we observed that both sexes were almost equally infected by Ascaris. This might be due to the fact that both males and females had the same probability to be exposed to risk factors. Similar findings were reported by Seid et al. (23). In contrast, Wabo Poné et al. (9) noticed a significant difference between sex in their studies carried out in Dschang, Cameroon. We also observed that the prevalence of infection with Ascaris was age-dependent. This result was similar to studies conducted by Seid et al. (23) who found that age had an effect on Ascaris lumbricoides infections.

Concerning seasonal distribution of Ascaris lumbricoides infection among population, the results revealed that participants were slightly more infested in the rainy season than in dry season but without a significant difference $(p>0.05)$. This might be due to the fact that the population had equally the possibility to be exposed during the rainy and dry seasons.

According to Stephenson (32), the intensity of infection in terms of eggs per gram (EPG) of feaces is in relation to the parasite species involved. For instance, for Ascaris lumbricoides, EPG is light when less than 7000. Therefore, in this study, participants had light parasite load $(<7000)(388.89 \pm 464.878)$ due to MAD.

Regarding the associated risk factors, analysis of different variables of this study show that the main risk factors are dirty hands and untrimmed finger nails. This result corroborates the observation of Kattula et al. (33) on the prevalence and risk factors transmitted helminths infection among school children in their studies done in South India. 
The findings reported in this study showed that the rate of soil contamination was low, but it remains to be the most direct indicator of risk factor for human infection. Also, unclean hands and untrimmed finger nails were the risk factors identified for soil transmitted helminths infections among residents of Bazou. We think that it is necessary to promote measures that could help to reduce the soil transmitted helminths infections.

\section{ACKNOWLEDGEMENTS}

The authors wish to express their sincere thanks to the inhabitants of Bazou who participatated in this study.

\section{REFERENCES}

1. Tavalla M, Oormazdi H, Akhlaghi L, Razmjou E, Moradi LM., Shojaee S, Hadighi R, Meamar AR. Prevalence of parasites in soil samples in Tehran public places. African Journal of Biotechnology 2012; 11 (20): 4575-4578.

2. Bethony J, Brooker S, Albonico M, Geiger SM, Loukas AL, Diemert D, Hotez PJ. Soil transmitted helminthic infections: ascariasis, trichuriasis and hookworm. Lancet 2003; 367:1521-1532.

3. DCPP 2008. Deworming Children Brings Huge Health and Development Gains in Low-Income Countries. 1-4.

4. Sowemimo OA, Asaolu SO. Current status of soil-transmitted helminthiases among preschool and school-aged children from Ile-Ife, Osun State, Nigeria. Journal of Helminthology 2011; 85(3):234-238.

5. De Silva NR, Guyatt HL, Bundy DA. Morbidity and mortality due to Ascarisinduced intestinal obstruction. Transaction of the Royal Society of Tropical Medicine and Hygiene 1997; 91:31-36.

6. WHO. Schistosomiasis and géohelminthiasis: action of prévention and control. 2004; 1-5.

7. CDC. Parasites: Soil-transmitted Helminths. Global Health - Division of Parasitic Diseases. 2013; 1-7.
8. Martuscelli Q.A. Frequency of helminth infections in children of Mexico. Rev Mex Ped. 1987; 36:111-115.

9. Wabo Poné J, Mpoame Mbida, Nkeng E, Alango P, Bilong Bilong CF. Prevalence and intensity of infections of three neglected tropical diseases in patients consulted at a traditional health care centre in Dschang West Cameroon. Tropical Parasitology 2012; 2 (1): $1-5$.

10. Debalke S, Amare W, Jahur N, Mekonnen Z. Soil transmitted helminths and associated factors among school schoolchildren in gorvernment and private primary school in Jimma Town, Southwest Ethiopia. Ethiopian Journal of Health Sciences 2013; 23(3): 1-6.

11. Tchuenté LA, N'goran EK. Schistosomiasis and soil-transmitted helminthiasis control in Cameroon and Côte d'Ivoire: implementing control on a limited budget. Journal of Parasitology 2009; 136 (13):1739-45.

12. Olaniyi J, Ekundayo, Muktar H, Aliyu P, Pauline EJ. A review of intestinal helminthiasis in Nigeria and the need for school-based intervention. Journal of Rural and Tropical Public Health 2007; 6: 33-39.

13. Daniel W. Biostastics a foundation for analysis in health scince. Thon willey and sonsinic 1995; New York, USA.

14. Euzeby J. Expérimental diagnosis of animals helminthosis (domesticated animals, laboratory animals, primates). Veterinary helminthology practicals. Book 1. Generalities: Diagnostic ante-morten. Edition "veterinary service techniques informations" Paris, 1982: 1-349.

15. Thienpont D, Rochett F, Vanparijs O. Coprological diagnosis of helminthosis. Janssen Research foundation. Beerse foundation, Belgium, 1979:1-187.

16. Soulsby EJL. Helminths, Arthropods and Protozoa of domesticated animals.7ed .Baillere. Tindal, London, 1982; 1-809.

17. Hanafi FZ, Yousseff ME, Abdel-Wahab FM. Soil as vehicle of parasitic infection to inhabitans of Talkha, Dakahlia Governorate. $J$ Egypt Soc Parasitol. 1987; 17 (1):135-145. 
18. Shrestha A, Rai SK, Basnyat SR, Rai CK, Shakya B. Soil transmitted helminthiasis in Kathmandu, Nepal. Katmandu University Medical Journal 2006; 1-3.

19. Appleton CC, Gouws E. The distribution of common intestinal nematodes along an altitudinal transect in KwaZulu-Natal, South Africa. Annual of Tropical Medicine and Parasitology 1996; 90:181-188.

20. Bojar H, Klapec T. Contamination of Soil with eggs of géohelminths in recreational areas in the Lublin Region of Poland. Annals of Agricultural and Environmental Medicine 2012; 19(2): 267-270.

21. Odoba B, Otalu JR, Balogun BJ. Prevalence of helminth parasites eggs in pupils and playing grounds of some selected primary schools in Zaria, Nigeria. World Journal Life Science and Medical Research 2012; 2 (5):192-199.

22. Smyth JD. Animal parasitology. Cambridge university press, Cambridge, law price editions, 1996: 1-549.

23. Seid M, Dejenie T, Tomass Z. Prevalence of intestinal helminths and associated risk factors in Rural school-children in Were-Abaye Sub District, Tigray Region, Northern Ethiopia. Acta Parasitologica Globalis 2015; 6(1): 29.

24. Schad GA, Chowdhury AB, Dean CG, Kochar VK, Nawalinski TA, Thomas J, Tonascia JA. Arrested development in human hookworm infections: an adaption to a seasonally unfavorable external environment. Science 1973; 180:502-504.

25. Uga S, Ono K, Kataoka N, Safriah A, Tantular IS, Dachlan YP, Ranuh IG. Contamination of soil with parasites eggs in Surabaya, Indonesia. Southeast Asian Journal Tropical Medicine Hygiene Public Health 1995; 26 (4): 730-734.

26. Stojcevic D, Susic V, Lucinger S. Contamination of soil and sand with parasite elements as a risk factor for human health in public parks and playgrounds in Pula. Veterinarski Archieves 2010; 80 (6): 733-742.

27. Komiya Y, Yasuraoka Y. Environmental factors influencing transmission. Medicine Parasitology 1966; 3:100-117.

28. Amadi E, Uttah E. "Impact of physicochemical factors of contaminated foci on the survival of geohelminths in Abua Communities, Niger Delta Nigeria," Journal of Applied Science and EnvironmentalManagement 2010; 14(4): 117.

29. Chukwuma NC, Ekejindu IM, Agbakoba NR., Ezeagwuna DA, Anaghalu IC, Nwosu DC. The prevalence and risk factors of geohelminth infections among primary school children in Ebenebe Town, Anambra State, Nigeria. Middle-East Journal of Scientific Research 2009; 4(3): 211-215.

30. Nkengazong L, Njiokou F, Wanji S, Teukeng F, Enyong P, Asonganyi T. Prevalence of soil transmitted helminths and impact of Albendazole on parasitic indices in Kotto Barombi and Marumba II villages (SouthWest Cameroon). African Journal of Environmental Science and Technology 2010; 4 (3):115-121.

31. Richardson JD, Richardson RK, Callahan DK, Gross J, Tsekeng P, Dondji B, Richardson EK. Geohelminth infections in rural Cameroonian villages. Comparative Parasitology 2011; 78(1): 161-179.

32. Stephenson LS. The impact of heminth infection on human nutrition. Shistosomes and soil transmitted, helminth. Taylor and Francis, London. 1987:1- 233.

33. Kattula D, Sarka R., Ajjampur, SSR, Minz S, Levecke B, Muliyil J, Kang G. Prevalence \& risk factors for soil transmitted helminth infection among school children in South India. Indian Journal Medical Research 2014; 1-3. 